\title{
Correspondence
}

\section{Using the discharge interview to evaluate a mental health unit}

\section{DeAr SiRs}

Methods used to evaluate mental health treatment programmes often neglect the voice of patients.

A total of 50 patients were interviewed on the day of discharge from the mental health unit to assess opinions about treatment and mental health unit conditions. Three questions were asked.

(a) What did you like best about the mental health unit, that is, what helped you the most?

(b) What did you dislike about the mental health unit, that is, what helped you the least?

(c) Do you have any suggestions for improvement in the mental health unit programmes or functioning?

Patients could give more than one response.

(a) Staff in general, their caring and understanding attitude was the category most often mentioned $(70 \%)$.

(b) The homely and friendly atmosphere of the mental health unit $(20 \%)$.

(c) Food (15\%).

(d) Medications ( $10 \%)$.

(e) Freedom (10\%).

(f) Confidentiality, privacy, recreational activities and help with insight were also found beneficial.

(g) As to dislikes, $25 \%$ of patients found nothing of note.

(h) Boredom was mentioned by $6 \%$

(i) Other points mentioned were gloomy decoration of the unit, confined space, a depressing day room, noise, the long interval between lunch and tea, the number of people present in the weekly review meetings, no clear guidelines as to the "rules" on the unit and a library with a poor choice of literature.

(j) Almost $35 \%$ of patients had no suggestions for improving the mental health unit programme.

(k) More activities were wanted by $10 \%$.

(l) A smaller percentage suggested: name badges for staff, seeing a doctor on a one-to-one basis, a games room with snooker and darts, provision of a tumble drier, installation of an additional payphone and means of obtaining change for this, more occupational therapy activities and group therapy, sewing and knitting classes, a designated non-smoking area, re-organising the day room, gym equipment, organised walks and better food.
The interview technique used was suggested by Keith-Spiegel et al (1970). Most patients were able to make a definite decision regarding the most beneficial aspects of their treatment.

Of particular interest was the high percentage of patients who chose staff kindness and understanding as the most favourable aspect. The role of the mental health unit in providing a favourable atmosphere in which to recover suggests that what pleases patients most is the way in which the unit meets their dependency needs.

Frequently mentioned beneficial aspects were staff attitude, food, medication and recreational activities. Many patients offered no suggestions for improvement. However, some offered reasonable and clever suggestions, which would be relatively easy to implement.

This study raises questions concerning the role which patient opinion should play in the improvement of the mental health unit's treatment programmes, aiming to meet the best interests of patients by being more sensitive to their needs.

West Cumberland Hospital
Whitehaven, Cumbria

S. H. Kamlana

Reference

Keith-Spiegel, P., Grayson, H. M. \& Spiegel, D. (1970) Using the discharge interview to evaluate a psychiatric hospital. Mental Hygiene, 54, 298-300.

\section{Follow-up of discharges by Mental Health Review Tribunals}

As a medical member of the Mental Health Review Tribunal, I should like to draw attention to a deficiency in the present Tribunal system. This is the lack of any mechanism for the follow-up of the Tribunal's decisions, in particular for patients who are discharged. What happens to them would seem a good test and audit of the tribunal's value, fairness, cost-effectiveness, and efficiency.

Many consultant psychiatrists can cite instances of patients discharged by Tribunals who have soon afterwards needed treatment and hospital care, perhaps under new detention orders. At present, this evidence is anecdotal: a wrong decision by a Tribunal can have serious consequences so it is important to discover how mistakes arise. A Tribunal might seem to be naive if it has discharged a patient on the basis 
of how well the patient presents at the Tribunal. Clearly, psychiatric patients can be mentally ill, and potentially disturbed and violent, but conduct themselves normally at a hearing.

When a Tribunal has reached an apparently wrong decision, this prompts the question of whether all the facts have been put before it. Sometimes there are inconsistencies between reports from the consultant, nurse and social worker. Often reports are undated. It is disconcerting for Tribunal members if they are faced with staff standing in for the professionals directly responsible for the care of the patient, and who are answering to reports compiled by others. Junior members of staff might feel intimidated and not do their case justice.

A form of standard questionnaire to cover points especially relevant to the Tribunal's decision-making might be a useful adjunct to complement psychiatric, nursing and social reports. Perhaps, when a Tribunal does decide to discharge, the responsible medical officer could be called back to discuss the implications of discharging the patient. It would be helpful if consultants could inform their Tribunal office of any cases where a Tribunal's decision has gone wrong.

\section{Meanwood Park Hospital} Leeds LS6 4QB

Douglas A. Spencer

\section{Involvement in patient care by managerial staff}

Dear Sirs

NHS non-clinical management staff are often considered remote from day to day problems of patient care dealt with by the clinical multidisciplinary team. The following case provides an example of direct involvement in patient care by the Mental Health Service Manager at a South Wales hospital.

A shy and anxious 20-year-old woman had been attending a psychiatric day hospital for two years. Referred by her GP for sub-clinical anorexia nervosa, she also had great difficulty in social relationships. She was a highly talented artist and had been runner-up in a nationwide competition for book illustrations. During her stay she gradually built up good relationships with staff and her psychiatric problems improved. Her enthusiasm and skill in painting and sculpting were encouraged and she expressed an interest in going to the local art college. After meeting with a tutor there, she was advised to apply, put together a portfolio of her work, and attend for interview. She became extremely anxious at the prospect of an interview and the staff felt she needed interview training.
The Mental Health Service Manager was approached for advice and offered to perform mock interviews with the patient. Three were held over one month, lasting 30-45 minutes, during which a dramatic improvement was noted in her presentation, confidence, and response to questioning. She successfully completed the real interview and was offered a place at the Art College.

This seems to be the first example where a member of NHS managerial staff has been directly involved in patient care. We would be interested to know whether there are other examples.

IMAD M. ALI

\section{East Glamorgan Hospital}

Church Village

South Wales

Day Hospital

ANNETte Evans

East Glamorgan Hospital

South Wales

\section{Definition of nearest relative, Section 3 , Mental Health Act}

DeAr Sirs

When a patient is to be admitted under Section 3 of the Mental Health Act, on the application of an Approved Social Worker, the nearest relative is required to given consent. If that relative objects to the application being made then the Section 3 cannot proceed.

I report a recent occurrence where the definition of the nearest relative was misunderstood.

The occurrence concerned a patient in the manic phase of a long standing unstable bipolar disorder. The responsible consultant decided, on a Bank Holiday Sunday, to proceed with compulsory ECT. Two medical recommendations were provided for admission under Section 3. The Approved Social Worker was informed that the patient had no living relative in the United Kingdom but had nominated a friend to act as the nearest relative. This friend refused to agree to the Section 3 and the Approved Social Worker decided that he could not proceed with an application.

The Act defines who should be regarded as a relative and in the absence of such a person makes provision for the appointment by the County Court of a person to exercise the functions of the nearest relative. If it is not possible for the Approved Social Worker to ascertain who is the patient's nearest relative within the meaning of the Act or if he believes that the patient has no nearest relative then he can make an application under Section 3 without consultation taking place. An application to the County 